\title{
Mycoplasma pneumoniae-associated mild encephalitis/encephalopathy with a reversible splenial lesion: report of two pediatric cases and a comprehensive literature review
}

Norishi Ueda ${ }^{*}$, Satoshi Minami ${ }^{1}$ and Manabu Akimoto ${ }^{2}$

\begin{abstract}
Background: No literature review exists on Mycoplasma pneumoniae-associated mild encephalitis/encepharopathy with a reversible splenial lesion (MERS).

Methods: M.pneumoniae-associated MERS cases were searched till August 2016 using PubMed/Google for English/ other-language publications and Ichushi (http://www.jamas.or.jp/) for Japanese-language publications. Inclusion criteria were children fulfilling definition for encephalitis, M.pneumoniae infection, and neuroimaging showing hyperintensity in the splenium of the corpus callosum (SCC) alone (type I) or SCC/other brain areas (type II).

Results: We described two children with type I and II M.pneumoniae-associated MERS. Thirteen cases found by the search and our 2 cases were reviewed. Mean age, male/female ratio, duration of prodromal illness was 8.3 years, 1.5 and 3.5 days. The most common neurological symptom was drowsiness, followed by abnormal speech/behavior, ataxia, seizure, delirium, confusion, tremor, hallucination, irritability, muscle weakness, and facial nerve paralysis. Fever was the most common non-neurological symptom, followed by cough, headache, gastrointestinal symptoms, headache, lethargy and dizziness. Seizure and respiratory symptoms were less common. All were diagnosed for $M$. pneumoniae by serology. Cerebrospinal fluid (CSF) M.pneumoniae was undetectable by PCR in the 3 patients. Three patients were clarithromycin-resistant. Leukocytosis, positive C-reactive protein, hyponatremia, CSF pleocytosis and slow wave on electroencephalography frequently occurred. All except 2 were type I MERS. Neuroimaging abnormalities disappeared within 18 days in the majority of patients. All type I patients completely recovered within 19 days. Two type II patients developed neurological sequelae, which recovered 2 and 6 months after onset.
\end{abstract}

Conclusions: Prognosis of M.pneumoniae-associated MERS is excellent. Type II MERS may increase a risk of neurological sequelae.

Keywords: Encephalitis, MERS, Neuroimaging, Mycoplasma pneumoniae, Splenium of the corpus callosum

\footnotetext{
* Correspondence: nueda@mattohp.com

${ }^{1}$ Department of Pediatrics, Public Central Hospital of Matto Ishikawa, 3-8

Kuramitsu, Hakusan 924-8588, Ishikawa, Japan

Full list of author information is available at the end of the article
} 


\section{Background}

Clinically mild encephalopathy/encephalitis with a reversible splenial lesion (MERS) is a clinicoradiological entity with varied etiologies, characterized by a reversible lesion with homogeneously reduced diffusion in the corpus callosum, and often associated with symmetrical white matter lesions on neuroimaging [1]. The most common causes of MERS in children are infections, including rotavirus and influenza virus [2-4]. According to the findings on neuroimaging, MERS is classified into type I involving solitary hyperintensity lesions in the splenium of the corpus callosum (SCC) and type II involving hyperintensity lesions in the SCC and other brain areas [5]. In general, the most common neurological symptom in type I MERS with varied etiologies has been reported to be delirious behavior, followed by consciousness disturbance, and seizures, all of which completely recover within a month [1].

Mycoplasma pneumoniae (M.pneumoniae) is a major cause of community-acquired pneumonia (CAP), accounting for $15-20 \%$ of CAP cases in adults and up to $40 \%$ of cases in children, especially in those aged 5-14 years [6]. M.pneumoniae-associated encephalitis is a common cause of encephalitis in children, occurring in 0.1 cases per 100,000 populations of $\leq 19$ years of age and in $3.2-$ $7.0 \%$ of patients with M.pneumoniae infection [7-10], of which up to $64 \%$ of cases have neurological sequelae $[8,9]$. However, M.pneumoniae-associated MERS occasionally occurs in children, and thus clinical features including neurological symptoms in M.pneumoniaassociated MERS remain unknown.

Here, we describe two pediatric cases of type I and II M.pneumoniae-associated MERS. To the best of our knowledge, the latter case of type II MERS is the first case of M.pneumoniae-associated MERS showing the hyperinteensity lesions in the SCC and the cerebellum. Currently, there is no comprehensive review on M.pneumoniae-associated MERS, and the difference in clinical features, neuroimaging findings, and outcome between type I and II MERS remains elusive. In the present study, pediatric cases of M.pneumoniae-associated MERS reported in the literature were searched, and a total of cases including our cases were reviewed to clarify clinical features, neuroimaging and outcome of the disease.

\section{Methods}

\section{Literature search}

A literature search for pediatric cases of M.pneumoniaeassociated MERS was conducted from November 2004 till August 2016 using PubMed and Google Scholar data base for Chinese-, Croatian-, Czech-, Danish-, English-, French-, German-, Hungarian-, Italian-, Korean-, Polish-, Portuguese-, Russian-, Spanish-, and Turkish-language publications as well as using Ichushi Web data base (http:// www.jamas.or.jp/) for Japanese-language publications. The search was performed using the following full keywords; 'Mycoplasma pneumoniae, 'encephalitis', 'encephalopathy', 'magnetic resonance imaging,' 'mild encephalitis/encephalopathy with a reversible splenial lesion', 'neuroimaging' and 'splenium of the corpus callosum'. Pediatric cases of M.pneumoniae-associated MERS reported in the literature and our recent cases were reviewed to clarify its clinical and demographic features, the findings on neurological imaging, and outcome. This study has been approved by the ethical committee of our institution.

\section{Selection criteria for case reports}

Case reports were eligible and included in the analysis when they met the following inclusion criteria. Children $\leq 15$ years of age who fulfilled; 1) the clinical definition for acute encephalitis [9], 2) the diagnosis of M.pneumoniae infection was confirmed by either serologic tests or PCR (polymerase chain reaction) assay for detection of M.pneumoniae, 3) the etiological case definition for acute encephalitis caused by M.pneumoniae, namely, "confirmed" (detection of M.pneumoniae by PCR in cerebrospinal fluid (CSF) or of intrathecal synthesis of specific antibodies), "probable" ( $\geq 4$-fold rise in specific serum antibody titer using paired serum samples), or "possible" (detection of M.pneumoniae by PCR in throat swab specimens and/or single increased specific serum antibody titer), were considered cases [9], 4) the brain MRI revealed hyperintensity lesions in the SCC alone (type I) or in the SCC and other brain areas (type II) [5], and 5) data for demographic and clinical characteristics were reported.

\section{Data extraction}

The following variables were extracted: patient characteristics (e.g., age, sex), acute neurological and non-neurological symptoms, duration of prodromal nonneurological symptoms prior to the onset of neurological symptoms, presence or absence of macrolide (clarithromycin) resistance defined by the absence of defervescence within $72 \mathrm{~h}$ after initiation of clarithromycin [11], laboratory data, including white blood cell (WBC) count in the peripheral blood, serum levels of $\mathrm{C}$-reactive protein (CRP) and sodium, presence or absence of pleocytosis in CSF, findings on electroencepharography (EEG), initial and follow-up neuroimaging, duration till recovery of clinical symptoms and of abnormal findings on neuroimaging, and outcome including neurological sequelae.

\section{Results \\ Case description \\ Case 1}

A previously healthy 14-year-old boy with a 4-day history of fever and cough was referred to our hospital due to clinical deterioration despite clarithromycin treatment. $\mathrm{He}$ 
had no remarkable medical or drug history. On admission (day 1), he was alert without any neurological abnormalities. Laboratory investigations revealed normal WBC count $(7,680 / \mu \mathrm{L}$; normal range; $3,400-10,000 / \mu \mathrm{L})$, normal blood urea nitrogen (11 mg/dL, normal range; $\leq 21 \mathrm{mg} /$ $\mathrm{dL})$, slightly elevated serum creatinine $(1.03 \mathrm{mg} / \mathrm{dL}$, normal range $0.6-1 \mathrm{mg} / \mathrm{dL})$, hyponatremia $(134 \mathrm{mEq} / \mathrm{L}$; normal range; $135-145 \mathrm{mEq} / \mathrm{L}$ ), and positive CRP (3.4 mg/ $\mathrm{dL}$; normal range; $<0.3 \mathrm{mg} / \mathrm{dL}$ ). Serum levels of calcium, magnesium, glucose and the liver function test were normal. Serum anti-M.pneumoniae IgM antibody using a rapid enzyme immunoassay (EIA, Immunocard ${ }^{\circledR}$ Mycoplasma, Meridian Bioscience Inc., $\mathrm{OH}$, USA) was negative. Antigens of influenza virus and adenovirus in the throat swab specimens were negative. Urinalysis was normal. Analysis of CSF was not performed.

A chest X-ray revealed dense infiltration in the bilateral lower lobes, indicative of pneumonia. Intravenous minocycline (100 mg/day) was administered for the treatment of M.pneumoniae pneumonia. In the following evening, he became afebrile but developed abnormal speech and hallucinations. In the morning on day 3 , he suddenly developed delirious behavior followed by drowsiness. Glasgow Coma Scale (GCS) score was 8 (E3, V1, M4). The brain MRI revealed hyperintensity lesions in the SCC on diffusion- and T2-weighted images (Fig. 1a and b). Intravenous dexamethasone and acyclovir were administered. He rapidly improved and was fully conscious in the evening on day 3. Neuroimaging on day 7 revealed disappearance of hyperintensity lesions in the SCC (Fig. 1c and d). Laboratory investigations revealed negative CRP, while seroconversion of serum anti-M.pneumoniae IgM antibody was noted. He was discharged without neurological sequelae on day 7 .

\section{Case 2}

A previously healthy 8-year-old girl with 1-day history of cough, headache, fever, lethargy, vomiting and diarrhea followed by drowsiness and seizures for $\sim 20 \mathrm{~s}$ was referred to our hospital. She had no remarkable medical or
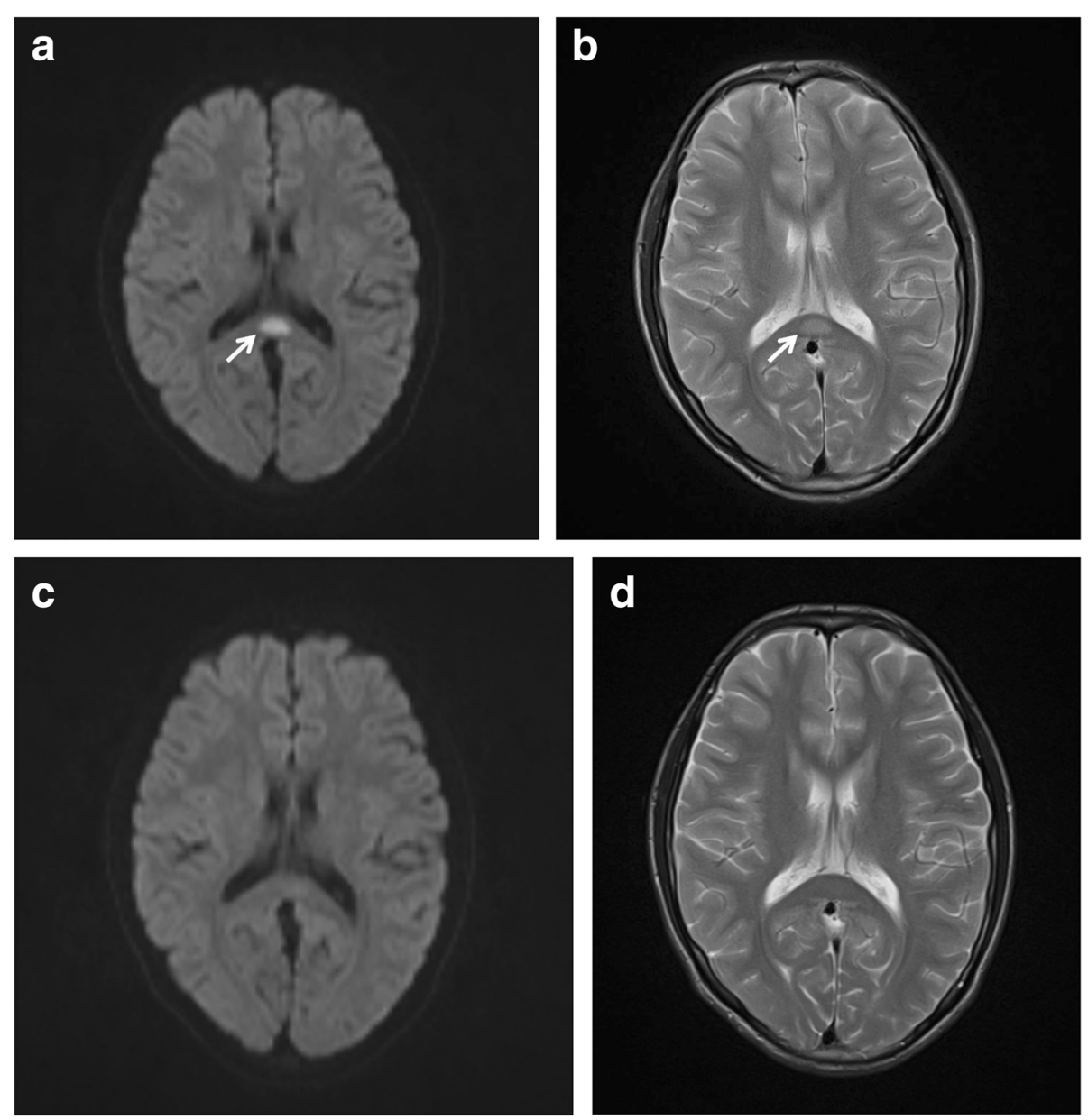

Fig. 1 The brain magnetic resonance imaging (MRI) in case 1. The brain MRI on day 3 after admission revealed high intensity lesions (arrows) in the splenium of the collupus callosum (SCC) on diffusion- (a) and T2- weighted images (b), which disappeared on day 7 (c and $\mathbf{d}$ ) 
drug history. On the same day, her younger brother was admitted to our hospital because of pneumonia due to M.pneumoniae diagnosed by pulmonary manifestation, chest X-ray finding, and positive M.pneumoniae-specific IgM. On admission (day 1), she was drowsy; GCS score was 8 (E3, V1, M5). Her body temperature was $38.3{ }^{\circ} \mathrm{C}$, and the blood pressure was normal $(108 / 68 \mathrm{mmHg})$. Physical examination revealed neither nuchal rigidity nor neurological abnormalities. Laboratory investigations revealed that WBC count $(6,480 / \mu \mathrm{L})$, serum levels of CRP, calcium, magnesium, glucose, the liver function test and urinalysis were within the normal range. However, hyponatremia $(132 \mathrm{mEq} / \mathrm{L})$ and positive serum anti-M.pneumoniae IgM antibody were noted. Serum IgM antibody against Epstein-Barr virus capsid antigen was negative but IgG antibody was positive, indicative of previous infection. Antigens of influenza virus and adenovirus in the throat swab specimens, and those of rotavirus, norovirus and adenovirus in the stool specimens were negative. Stool culture revealed no pathogenic bacteria. Analysis of CSF was not performed.
A chest X-ray revealed increased bronchial markings in the right lower lobe. The brain computed tomography (CT) and the EEG revealed no abnormalities. Intravenous fluid therapy was immediately given, followed by administration of an anticonvulsant, diazepam suppository $(6 \mathrm{mg})$, for prophylaxis of further convulsions. Six hours later, her consciousness was fully recovered. On the following day, she started receiving oral minocycline ( $2 \mathrm{mg} / \mathrm{kg} /$ day). On day 5 , she suddenly developed headache, drowsiness, ataxia and intension tremor. The brain MRI revealed hyperintensity lesions in the SCC (Fig. 2a) and the left cerebellum (Fig. 2b) on diffusion-weighted images. Similar signal characteristics were noted in the SCC and the left cerebellum on T2-weighted images.

Oral minocycline was switched to intravenous administration for additional 3 days. On day 6 , she became afebrile, rapidly improved, and was fully conscious without disturbance of gait, cognition, speech, swallowing and vision. However, she still had intension tremor, slight muscle weakness and disabled fine motor incoordination of the left hand. Neuroimaging on day 12 revealed disappearance of
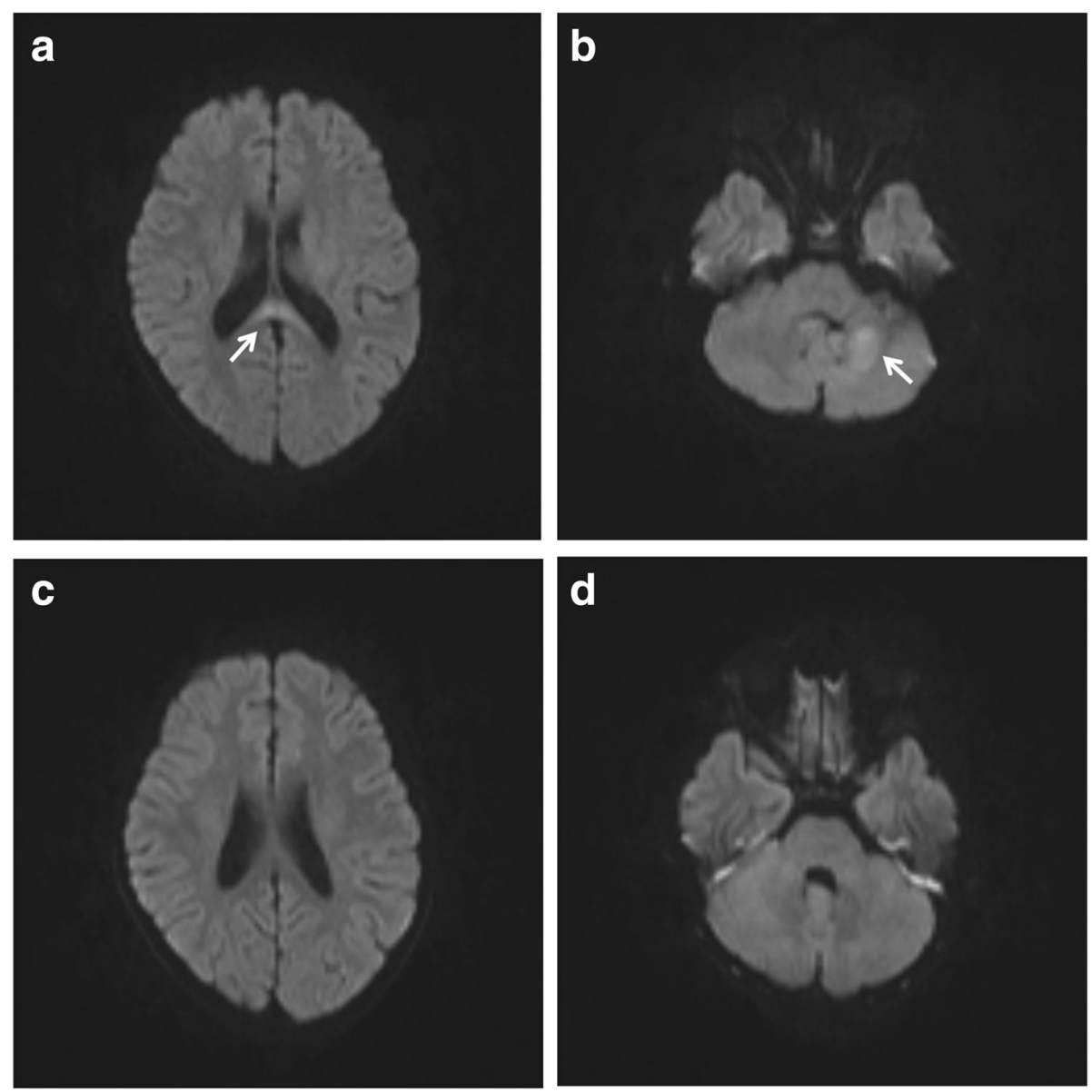

Fig. 2 The brain MRI in case 2. The brain MRI on day 5 revealed high intensity lesions (arrows) in the SCC (a) and the left cerebellum (b) on diffusion-weighted images, which disappeared on day 12 (c and $\mathbf{d}$ ) 
the hyperintensity lesions in the SCC and the left cerebellum (Fig. 2c and d). She was discharged on day 14 with slight disability of fine motor incoordination of the left hand, which completely recovered 2 months after the onset of the disease.

\section{Litterature review}

The literature search found 13 cases, including 4 Englishlanguage full reports (7 cases) [5, 12-14], 1 Japaneselanguage full report (1 case) [15] and 5 Japanese-language abstract-only reports (5 cases) [16-20]. Our recent 2 cases described above were added for a total of 15 cases with M.pneumoniae-associated MERS. Of the 15 patients, 5 and 10 patients were "probable" and "possible" cases, respectively, while none was "confirmed" case. Demographic, clinical characteristics, laboratory data, neuroimaging findings, and outcome of these patients are summarized in Table 1. Mean age, male/female ratio, and mean duration of prodromal illness before the onset of neurological symptoms were 8.3 years (range 2-14 years), 1.5 (9/6), and 3.5 days (range $1-8$ days), respectively. Of note, mean period of prodromal illness before the onset of neurological symptoms was shorter in the patients with type II MERS (1 day) than in those with type I MERS (3.8 days, range $1-8$ days).

As neurological symptoms, drowsiness $(12 / 15,80 \%)$ was the most common, followed by abnormal speech (5/ $15,33 \%)$, ataxia $(4 / 15,27 \%)$, seizure $(4 / 15,27 \%)$, delirium $(3 / 15,20 \%)$, abnormal behavior $(2 / 15,13 \%)$, confusion (2/ $15,13 \%)$, tremor $(2 / 15,13 \%)$, irritability $(2 / 15,13 \%)$, hallucination $(1 / 15,7 \%)$, muscle weakness $(1 / 15,7 \%)$, motor deterioration $(1 / 15,7 \%)$, and peripheral facial nerve paralysis $(1 / 15,7 \%)$. Among non-neurological symptoms, fever $(14 / 15,93 \%)$ was the most common, followed by cough $(8 / 15,53 \%)$, headache (7/15, $47 \%)$, gastrointestinal symptoms (abdominal pain, vomiting and diarrhea, 6/15, $40 \%$ ), lethargy (5/15, $33 \%)$, and dizziness $(1 / 15,7 \%)$. Prolonged fever ( $\geq 6$ days) developed in $58 \%$ (7/12) of the patients, in whom the information of duration of fever was available. Seven (47\%) of the 15 patients had no respiratory symptoms.

All patients were diagnosed by serologic tests. Eight (53\%) of the 15 patients were diagnosed by a single measurement of M.pneumoniae-specific antibody; there were 4 and 2 cases with positive IgM antibody as measured by EIA and enzyme-linked immunosorbent assay (ELISA), respectively, and in the remaining 2 patients, M.pneumoniae-specific antibody as measured by ELISA was positive but what type of antibody was unknown. Of these 8 patients with positive M.pneumoniae-specific antibody, 2 patients simultaneously showed positive M.pneumoniae DNA in the throat swab specimens by PCR. There was a 4-fold or more rise in serum antiM.pneumoniae antibody titer as measured by complement fixation test (CFT) in 1 case and by particle agglutination assay (PA) in 4 cases. Information of the method for serologic tests was not available in the remaining 2 cases. None of the patients underwent culture analysis.

Three patients showed clarithromycin resistance. Chest $\mathrm{X}$-ray or $\mathrm{CT}$ of the 7 patients examined revealed infiltration of the lobes $(n=5)$ or increased bronchial markings $(n=2)$. Leukocytosis $(>10,000 \mathrm{WBCs} / \mu \mathrm{L})$, positive CRP $(>0.3 \mathrm{mg} / \mathrm{dL})$ and hyponatremia $(<135 \mathrm{mEq} / \mathrm{L})$ were noted in $42 \%(5 / 12), 75 \%(9 / 12)$ and $44 \%(4 / 9)$ of the patients, respectively. CSF pleocytosis $(>10 \mathrm{WBCs} / \mu \mathrm{L})$ was found in $3(33 \%)$ of the 9 patients, three of whom showed negative M.pneumoniae in CSF as measured by PCR. The levels of interleukin (IL)-6 in CSF were elevated in a patient with type I MERS. EEG revealed slow wave in $63 \%(5 / 8)$ of the patients examined.

On neuroimaging, all except 2 patients showed type I MERS. Two patients were type II MERS; our case 2 with hyperintensity lesions in the SCC and the left cerebellar lesions, and other case with those in the SCC, center semiovale and parietal white matter bilaterally [5]. Hyperintensity lesions in the SCC and other brain areas on neuroimaging disappeared within 18 days in all except 4 patients including 3 with type I and 1 with type II MERS, in whom the lesions on the follow-up MRI disappeared 2-4 months after the initial MRI.

Antibiotic treatment included azithromycin (4/10), ciprofloxacin $(3 / 10)$, and minocycline $(3 / 10)$, while none received clarithromycin after the onset of MERS. Intravenous steroids were given to $42 \%(5 / 12)$ of the patients. All patients with type I MERS completely recovered within 19 days, while 2 patients with type II MERS developed neurological sequelae, which recovered 2 and 6 months, respectively, after the onset of the disease.

\section{Discussion}

There is some concern about the diagnostic tests for acute M.pneumoniae infection. Culture is impractical since the long time is required to get the results [21]. Serologic tests have been most widely used and a 4-fold rise in antibody titer in acute and convalescent sera is considered the "gold standard". However, the use of a single qualitative measurements of IgM has low sensitivity $(32-77 \%)[22,23]$, which increases $(88.6 \%)$ when paired sera are analysed [23]. Taking sera during both phases is too late for point-of-care diagnosis and difficult in children [22]. False-positive results occur since IgM remains detectable for several months following infection [21, 22]. False-negative results occur when serum is collected within 7 days after onset $[21,22]$ and in immunocompromised patients and infants $<6$ months of age, who often do not produce IgM [21]. PCR is highly sensitive and measures blood, CSF, and pharyngeal 
samples. False positive results occur due to colonization and prolonged shedding from previous infection [22]. False-negative results occur due to contamination, inhibitors in samples, or timing of sample collection [22]. Thus, the combination of PCR plus serology yields the most reliable results. Despite inadequate validity of serology and untested other respiratory pathogens, pulmonary symptoms, chest X-ray findings, IgM seroconversion and interfamilial M.pneumoniae infection episode strongly suggest that our cases are considered "possible" cases.

All except one case [5] were reported from Asia; Japan [12, 15-20] and China [13, 14], suggesting a role of racial factor(s) for M.pneumoniae-associated
MERS. As M.pneumoniae-associated encephalitis [7-10], M.pneumoniae-associated MERS predominantly occurs in children aged 2-14 years. Adult case of M.pneumoniaeassociated MERS was only reported [24]. Thus, young age may be a predisposing factor of M.pneumoniae-associated MERS. As M.pneumoniae-associated encephalitis [9] and MERS by other causes [14], male preponderance is noted in M.pneumoniae-associated MERS.

Extrapulmonary complications, in particular encephalitis, occurred more frequently in children with macrolideresistant than in those with macrolide-sensitive M.pneumoniae [25]. However, our study suggested that clarithromycin resistance is not a predisposing factor of M.pneumoniae-associated MERS.

Table 1 Pediatric cases of MERS associated with Mycoplasma pneumoniae infection

\begin{tabular}{|c|c|c|c|c|c|c|c|c|c|c|}
\hline Age (yrs) & Sex & $\begin{array}{l}\text { Duration of } \\
\text { prodromal } \\
\text { illness (d) }\end{array}$ & $\begin{array}{l}\text { Neurological } \\
\text { symptoms }\end{array}$ & $\begin{array}{l}\text { Non-neurological } \\
\text { symptoms }\end{array}$ & $\begin{array}{l}\text { Duration } \\
\text { of fever (d) }\end{array}$ & $\begin{array}{l}\text { Diagnosic } \\
\text { method for MP }\end{array}$ & $\begin{array}{l}\text { Diagnosis of } \\
\text { MP-associated } \\
\text { encephalitis }\end{array}$ & $M R$ & $\begin{array}{l}\text { Chest } \\
\text { X-ray/CT }\end{array}$ & $\begin{array}{l}\text { WBC } \\
\text { (cells/ } \mu \mathrm{L})\end{array}$ \\
\hline 13 & M & 1 & $\begin{array}{l}\text { Abnormal speech, } \\
\text { ataxia, confusion, } \\
\text { drowsiness }\end{array}$ & $\begin{array}{l}\text { Abd pain, fever, } \\
\text { lethargy }\end{array}$ & NA & $\operatorname{lgMAb/CFT}$ & probable & NA & NA & 7,950 \\
\hline 3 & $\mathrm{~F}$ & 3 & Drowsiness, seizure & $\begin{array}{l}\text { Diarrhea, fever, } \\
\text { vomiting }\end{array}$ & 6 & $\operatorname{lgMAb/EIA}$ & possible & NA & NA & normal \\
\hline 8 & M & 2 & $\begin{array}{l}\text { Ataxia, confusion, } \\
\text { drowsiness }\end{array}$ & Fever, lethargy & 6 & $\operatorname{lgMAb} / \mathrm{EI} A$ & possible & NA & NA & increased \\
\hline 9 & M & 1 & $\begin{array}{l}\text { Drowsiness, left } \\
\text { peripheral facial } \\
\text { nerve paralysis }\end{array}$ & $\begin{array}{l}\text { Fever, headache, } \\
\text { lethargy, vomiting }\end{array}$ & 2 & $\begin{array}{l}\text { IgMAb/ELISA } \\
M P(+) \text { in PS } \\
\text { by } P C R\end{array}$ & possible & NA & NA & 4,500 \\
\hline 12 & M & 6 & Drowsiness & $\begin{array}{l}\text { Cough, dizziness, } \\
\text { fever, headache, } \\
\text { lethargy, vomiting }\end{array}$ & 6 & $\begin{array}{l}\text { IgMAb/ELISA } \\
M P(+) \text { in PS } \\
\text { by } P C R\end{array}$ & possible & NA & IF & 8,100 \\
\hline 2 & M & 2 & $\begin{array}{l}\text { Abnormal speech, } \\
\text { irritability, motor } \\
\text { deterioration, seizure }\end{array}$ & $\begin{array}{l}\text { Abd.pain, fever, } \\
\text { vomiting }\end{array}$ & 2 & ELISA & possible & NA & NA & 11,600 \\
\hline 6 & M & 4 & $\begin{array}{l}\text { Abnormal speech, } \\
\text { delilium, drowsiness }\end{array}$ & $\begin{array}{l}\text { Abd.pain, fever, } \\
\text { headache }\end{array}$ & 4 & ELISA & possible & NA & NA & 12,600 \\
\hline 6 & M & 6 & Drowsiness, irritability & $\begin{array}{l}\text { Cough, fever, } \\
\text { headache }\end{array}$ & 10 & PA & probable & + & IBM & 11,800 \\
\hline 8 & $\mathrm{~F}$ & 1 & $\begin{array}{l}\text { Ataxia, muscle } \\
\text { weakness, tremor }\end{array}$ & Cough, fever & NA & PA & probable & NA & IF & 8,000 \\
\hline 10 & $\mathrm{~F}$ & 1 & Drowsiness & Cough & 0 & PA & probable & NA & IF & NA \\
\hline 12 & $\mathrm{~F}$ & 7 & $\begin{array}{l}\text { Abnormal behavior, } \\
\text { drowsiness, seizure }\end{array}$ & Fever & NA & NA & possible & NA & NA & NA \\
\hline 6 & $\mathrm{~F}$ & 4 & Delirium & Cough, fever & 8 & NA & possible & + & IF & NA \\
\hline 7 & M & 8 & $\begin{array}{l}\text { Abnormal speech, } \\
\text { drowsines }\end{array}$ & $\begin{array}{l}\text { Cough, fever, } \\
\text { headache }\end{array}$ & 6 & PA & probable & NA & NA & 16,400 \\
\hline 14 & M & 5 & $\begin{array}{l}\text { Abnormal speech/behavior, } \\
\text { delirium, drowsiness, } \\
\text { hallucinations }\end{array}$ & $\begin{array}{l}\text { Cough, fever, } \\
\text { headache }\end{array}$ & 5 & $\operatorname{IgMAb} / \mathrm{EIA}$ & possible & + & IF & 7,680 \\
\hline 8 & $\mathrm{~F}$ & 1 & $\begin{array}{l}\text { Ataxia, drowsiness, } \\
\text { intension tremor, seizure }\end{array}$ & $\begin{array}{l}\text { Cough, diarrhea, } \\
\text { fever, headache, } \\
\text { lethargy, vomiting }\end{array}$ & 9 & $\operatorname{IgMAb} / \mathrm{EI} A$ & possible & NA & IBM & 6,480 \\
\hline
\end{tabular}

$A b$ antibody, $A b d$ abdominal, $A Z T$ azithromycin, CFT complement fixation test, CIP ciprofloxacin, CR complete recovery, CRP C-reactive protein. CSF cerebrospinal fluid, $C T$ computed tomography, EEG electroencephalography, EIA enzyme immunoassay, ELISA enzyme-linked immusorbent assay, IBM increased bronchial markings, IF infiltration, IL interleukin, MINO minocycline, MERS mild encephalitis/encephalopathy with a reversible splenial lesion, MP Mycoplasma pneumoniae, MR macrolide (clarithromycin) resistance, $M R I$ magnetic resonance imaging, $P A$ particle agglutination assay, $P C R$ polymerase chain reaction, $P S$ pharyngeal swab sample, SCC splenium of the corpus callosum, SW slow wave, WBC white blood cell. $\uparrow$ increase, ND not done, NA not available 
Table 1 Pediatric cases of MERS associated with Mycoplasma pneumoniae infection (Continued)

\begin{tabular}{|c|c|c|c|c|c|c|c|c|c|c|c|}
\hline \multirow[t]{2}{*}{ Age (yrs) } & \multirow{2}{*}{$\begin{array}{l}\text { CRP } \\
(\mathrm{mg} / \mathrm{dl})\end{array}$} & \multirow{2}{*}{$\begin{array}{l}\mathrm{Na} \\
(\mathrm{mEq} / \mathrm{L})\end{array}$} & \multirow{2}{*}{$\begin{array}{l}\text { CSF } \\
\text { finding }\end{array}$} & \multirow[t]{2}{*}{$\mathrm{EEG}$} & \multirow{2}{*}{$\begin{array}{l}\text { MRI } \\
\text { findings }\end{array}$} & \multirow{2}{*}{$\begin{array}{l}\text { Time till } \\
\text { recovery of } \\
\text { MRI findings (d) }\end{array}$} & \multirow{2}{*}{$\begin{array}{l}\text { Time till clinical } \\
\text { recovery }(\mathrm{d})\end{array}$} & \multicolumn{2}{|l|}{ Treatment } & \multirow[t]{2}{*}{ Outcome } & \multirow[t]{2}{*}{ Ref } \\
\hline & & & & & & & & Antibiotics & $\overline{\text { Steroids }}$ & & \\
\hline 13 & 0.1 & NA & pleocytosis & SW & $\begin{array}{l}\text { type II, SCC, } \\
\text { center semiovale, } \\
\text { genu, parietal }\end{array}$ & 90 & 180 & CIP & - & $C R$ & [5] \\
\hline 3 & - & NA & normal & NA & type I & 60 & 3 & AZT & - & $C R$ & {$[12]$} \\
\hline 8 & + & NA & normal & NA & type I & 6 & 8 & $\mathrm{AZT}$ & + & $C R$ & [12] \\
\hline 9 & 1.6 & 127 & $\begin{array}{l}\text { normal } \\
\text { MP }(-) \text { in } \\
\text { CSF by PCR }\end{array}$ & SW & type I & 7 & 10 & $A Z T$ & - & $C R$ & [13] \\
\hline 12 & 1.4 & 139 & 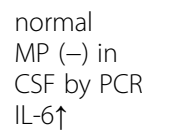 & SW & type I & 3 & 8 & $A Z T$ & - & $C R$ & [13] \\
\hline 2 & 6.6 & 136 & normal & normal & type I & 120 & 8 & NA & - & $C R$ & {$[14]$} \\
\hline 6 & 16.8 & 135 & normal & SW & type I & 67 & 19 & NA & + & $C R$ & {$[14]$} \\
\hline 6 & 0.33 & 135 & pleocytosis & SW & type I & 18 & 12 & CIP & - & $C R$ & [15] \\
\hline 8 & 5.72 & 136 & ND & NA & type I & 8 & 8 & NA & NA & $C R$ & {$[16]$} \\
\hline 10 & NA & NA & ND & NA & type I & 15 & 4 & NA & NA & $C R$ & [17] \\
\hline 12 & NA & NA & NA & NA & type I & NA & 10 & NA & + & $C R$ & [18] \\
\hline 6 & NA & NA & ND & NA & type I & 11 & 8 & CIP & NA & $C R$ & [19] \\
\hline 7 & 1.1 & 131 & $\begin{array}{l}\text { pleocytosis } \\
\text { MP (-) in CSF } \\
\text { by PCR }\end{array}$ & normal & type I & 4 & 4 & MINO & + & $C R$ & [20] \\
\hline 14 & 2.6 & 134 & ND & ND & type I & 7 & 7 & MINO & + & $C R$ & Case 1 \\
\hline 8 & $<0.3$ & 133 & ND & normal & $\begin{array}{l}\text { type II,SCC, } \\
\text { left cerebellum }\end{array}$ & 7 & 60 & MINO & - & $C R$ & Case2 \\
\hline
\end{tabular}

Disturbance of consciousness, delirious behavior and ataxia are common neurological symptoms in M.pneumoniae-associated MERS as MERS by other causes [3, 26]. In contrast to M.pneumoniae-associated encephalitis (48-67\%) [8, 27, 28], seizure is less common (27\%) in MERS due to M.pneumoniae as that by other causes (14-32\%) [3, 26], probably due to mild brain dysfunction in M.pneumoniae-associated MERS. This is supported by the EEG finding; normal to mild abnormality (i.e. slow wave) as in MERS by other causes [26] versus diffuse cortical dysfunction and focal epileptiform discharge in M.pneumoniae-associated encephalitis [27, 29]. It remains unknown how the SCC lesions cause neurological manifestations. The splenium is the posterior part of the corpus callosum, connecting different cortical areas, including occipital, parietal and temporal lobes [30]. Thus, the lesions in the SCC and other brain regions connecting SCC lead to various neurological manifestations [31]. Neuroimaging findings in type II MERS suggests that neurological symptoms in MERS may be due to the lesions in both the SCC and other brain regions connecting the SCC.

Fever is the most common non-neurological symptom as in M.pneumoniae-associated encephalitis [7-10, 29]. Prolonged fever ( $\geq 6$ days) is noted in the majority of the patients, while respiratory symptoms are less common (47 \%) as in M.pneumoniae-associated encephalitis $(\sim 44 \%)$ [7, 32]. Longer intervals between respiratory and CNS manifestations were associated with worse outcome in M.pneumoniae-associated encephalopathy [33]. However, short intervals in type II M.pneumoniae-associated MERS suggest that short period of prodromal illness before the onset of CNS manifestations may predict severe MERS as in M.pneumoniae-associated encephalitis [8].

Leukocytosis and positive CRP were associated with severe M.pneumoniae infection [34]. Prevalence of leukocytosis and positive CRP in the patients reported here is similar to that (57 and $71 \%$, respectively) in MERS by other causes [3]. Our and other cases of type II MERS [5] showed no leukocytosis and negative CRP, suggesting no predictive values of these parameters for worse outcome. Our study showed that CSF pleocytosis occurs more frequently in M.pneumoniae-associated MERS (33\%) than in MERS by other causes (0\%) [3], and its prevalence is similar to that (33-66 \%) in M.pneuminiae-associated encephalitis [8, 29, 35]. In contrast to M.pneumoniae-associated encephalitis [35], CSF pleocytosis does not seem to increase a risk of neurological sequelae or worse outcome. 
The mechanism by which the SCC lesions occur in MERS remains elusive. Hyponatremia has been proposed to reduce the intracellular osmotic pressure in the SCC, leading to transient edema [36]. Hyponatremia exacerbates the SCC injury [37]. However, hyponatremia occurs in less than a half of M.pneumoniae-associated MERS patients, similar to MERS by other causes (37-83 \%) $[3,14,26,36,38]$, suggesting that hyponatremia may be a modulator but not essential for development of the SCC lesions. As M.pneumoniae-associated encephalitis [7, 9, 33], PCR rarely detected M.pneuminiae in CSF of M.pneumoniae-associated MERS [13, 20], suggesting indirect mechanisms such as immune-mediated mechanism [1] rather than direct invasion of M.pneumoniae, leading to the SCC lesions. The levels of CSF IL- 6 were increased in MERS due to M.pneumoniae [13] and other causes [39]. IL-6 induces the SCC injury [40]. An oxidative stress marker in CSF was increased in MERS by other causes [39]. Low levels of glutathione reductase, anti-oxidant enzyme, in the corpus callosum [41] make the SCC more susceptible to oxidant injury. Proinflammatory cytokines, oxidants and reduced anti-oxidant enzymes may lead to the SCC lesions. Anti-N-methyl-D-aspartate receptor (NMDAR) antibody was detected in serum and CSF of M.Pneumoniae-associated encephalitis [42]. NMDARs are expressed in the SCC [43]. Thus, anti-NMDAR antibody may be a potential contributing factor to the SCC lesions [44].

M.pneumoniae-associated MERS is type I in almost all patients, while 2 (13 \%) patients developed type II MERS [5] including our case. In type I MERS by other causes, hyperintensity lesions in the SCC disappeared 3 days to 2 months following the initial MRI and $53 \%$ of the patients recovered within 1 week [45]. In M.pneumoniaeassociated MERS, the neuroimaging finding normalized $\sim 18$ days after the initial MRI in all except 4 ( 3 type I and 1 type II) [5, 12, 14], in which it normalized 2-4 months.

As MERS by other causes (31\%) [25], intravenous steroids were only given to $42 \%$ of the patients. Steroids are not essential other than treating concomitant infection partly because the natural history of M.pneumoniae-associated MERS is almost always excellent.

Despite high mortality (9\%) [10] and prevalence of neurologic sequelae (18-64 \%) in M.pneumoniae-associated encephalitis $[8,10,28]$, prognosis is excellent and neurological sequelae never develop in type I M.pneumoniae-associated MERS. All except 2 patients with type II MERS [5], including our case, fully recovered within 19 days after the onset. Neurological symptoms recovered as the neuroimaging finding improved. In contrast, our case and other case with type II MERS [5] developed neurological sequelae, which disappeared 2 and 6 months, respectively, after the onset, suggesting that prognosis of M.pneumoniae-associated MERS may depend on the extent of brain lesions affected.
Limitation of the present study includes its retrospective and observational nature, too small sample size, and inadequate validity of diagnostic method for M.pneumoniae infection in reported cases.

\section{Conclusions}

MERS could be associated with M.pneumoniae infection and M.pneumoniae-associated MERS predominantly occurs in children with male preponderance. Seizure and respiratory symptoms are less common. Despite excellent outcome in type I M.pneumoniae-associated MERS, there may be a risk of neurological sequelae in type II MERS, depending on the brain lesions affected. Short intervals between prodromal illness and CNS manifestations may be associated with type II MERS. Limitation of the present descriptive and retrospective study with small sample size warrants further investigations to clarify clinical features and risk factors of MERS that could be associated with M.pneumoniae infection.

\section{Abbreviations \\ CAP: Community-acquired pneumonia; CFT: Complement fixation test; CNS: Central nervous system; CRP: C-reactive protein; CSF: Cerebrospinal fluid; CT: Computed tomography; EEG: Electroencephalography; EIA: Enzyme immunoassay; ELISA: Enzyme-linked immunosorbent assay; GCS: Glasgow coma scale; IL: Interleukin; M.pneumoniae: Mycoplasma pneumoniae; MERS: Mild encephalitis/encephalopathy with a reversible splenial lesion; MRI: Magnetic resonance imaging; NMDARs: N-methyl-D-aspartate receptors; PCR: Polymerase chain reaction; SCC: Splenium of the corpus callosum; WBC: White blood cell}

\section{Acknowledgements}

The authors are grateful to Yukiya Nobana, Division of Health Information Management, Public Central Hospital of Mattoh Ishikawa, Hakusan, Ishikawa, Japan, for his help in preparation of graphics.

\section{Funding}

None is declared.

Availability of data and materials

All data supporting the conclusions of this study are provided in this article.

Authors' contributions

$\mathrm{NU}$ is entirely responsible for the study, including the design of the study, data collection, interpretation of the data, and writing the manuscript. SM contributed to the management of the patients' care, and MA analyzed the findings on neuroimaging of the patients described in case presentation. All authors read and approved the final manuscript.

Competing interests

The authors declare that they have no competing interests.

\section{Consent for publication}

Written informed consent was obtained from the patients for publication of our two cases and any accompanying images. A copy of the written consent from the parents of each patient is available for review by the Editor of this journal.

Ethics approval and consent to participate

The study has been approved by the ethics committee of our institution. Consent to participate is not applicable. 


\section{Author details}

'Department of Pediatrics, Public Central Hospital of Matto Ishikawa, 3-8 Kuramitsu, Hakusan 924-8588, Ishikawa, Japan. ²Department of Radiology، Public Central Hospital of Matto Ishikawa, Hakusan, Ishikawa, Japan.

\section{Received: 1 July 2016 Accepted: 27 October 2016}

\section{Published online: 11 November 2016}

\section{References}

1. Takanashi J. Two newly proposed infectious encephalitis/encephalopathy syndromes. Brain Dev. 2009;31:521-8.

2. Karampatsas K, Spyridou C, Morrison IR, Tong CY, Prendergast AJ. Rotavirusassociated mild encephalopathy with a reversible splenial lesion (MERS)case report and review of the literature. BMC Infect Dis. 2015;15:446.

3. Ka A, Britton P, Troedson C, Webster R, Procopis P, Ging J, et al. Mild encephalopathy with reversible splenial lesion: an important differential of encephalitis. Eur J Paediatr Neurol. 2015;19:377-82.

4. Kashiwagi M, Tanabe T, Ooba C, Masuda M, Shigehara S, Murata S, et al. Differential diagnosis of delirious behavior in children with influenza. Brain Dev. 2015;37:618-24.

5. Notebaert A, Willems J, Coucke L, Van Coster R, Verhelst H. Expanding the spectrum of MERS type 2 lesions, a particular form of encephalitis. Pediatr Neurol. 2013;48:135-8.

6. Brown RJ, Nguipdop-Djomo P, Zhao H, Stanford E, Spiller OB, Chalker VJ. Mycoplasma pneumoniae epidemiology in England and Wales: a national perspective. Front Microbiol. 2016;7:157.

7. Christie L, Honarmand S, Talkington DF, Gavali SS, Preas C, Pan CY, et al. Pediatric encephalitis: what is the role of Mycoplasma pneumoniae? Pediatrics. 2007;120:305-13.

8. Bitnun A, Ford-Jones EL, Petric M, MacGregor D, Heurter H, Nelson S, et al. Acute childhood encephalitis and Mycoplasma pneumoniae. Clin Infect Dis. 2001:32:1674-84.

9. Meyer Sauteur PM, Moeller A, Relly C, Berger C, Plecko B, Nadal D. Swiss pediatric surveillance unit (SPSU). Swiss national prospective surveillance of paediatric Mycoplasma pneumoniae-associated encephalitis. Swiss Med Wkly. 2016;146:W14222.

10. Pillai SC, Hacohen Y, Tantsis E, Prelog K, Merheb V, Kesson A, et al. Infectious and autoantibody-associated encephalitis: clinical features and long-term outcome. Pediatrics. 2015;135:e974-84.

11. Seo YH, Kim JS, Seo SC, Seo WH, Yoo Y, Song DJ, et al. Predictive value of Creactive protein in response to macrolides in children with macrolide-resistant Mycoplasma pneumoniae pneumonia. Korean J Pediatr. 2014;57:186-92.

12. Osuka S, Imai H, Ishikawa E, Matsushita A, Yamamoto T, Nozue H, et al. Mild encephalitis/encephalopathy with a reversible splenial lesion: evaluation by diffusion tensor imaging. Two case reports. Neurol Med Chir (Tokyo). 2010; 50:1118-22.

13. Yuan ZF, Shen J, Mao SS, Yu YL, Xu L, Jiang PF, et al. Clinically mild encephalitis/encephalopathy with a reversible splenial lesion associated with Mycoplasma pneumoniae infection. BMC Infect Dis. 2016:16:230.

14. Chen WX, Liu HS, Yang SD, Zeng SH, Gao YY, Du ZH, et al. Reversible splenial lesion syndrome in children: Retrospective study and summary of case series. Brain Dev. 2016;38:915-27.

15. Kawagoshi R, Ono J. A case of Mycoplasma-associated encephalitis/ encephalopathy with a reversible splenial lesion. Meiwa lgaku Zasshi. 2015; 2:35-40. [in Japanese].

16. Tokunaga Y. A female case of mild encephalopathy with a reversible splenial lesion associated with Mycoplasma pneumoniae infection. No to Hattatsu. 2008;40(Suppl):396. [in Japanese].

17. Ohgoshi Y, Sakai T, Nonaka S, Nakamura Y, Hosaki A, Bessho F. A case of mild encephalitis/encephalopathy with a reversible splenial lesion associated with Mycoplasma pneumonia. Nihon Shonika Gakkai Zasshi. 2009;113:350. [in Japanese].

18. Kubo K, Ogawa M, Ichikawa S, Saito R, Senju A, Saito H, et al. Three cases of mild encephalitis/encephalopathy with a reversible splenial lesion (MERS). Nihon Shonika Gakkai Zasshi. 2010;114:1965. [in Japanese].

19. Nakamoto T, Tanaka K, Koga H, Kan N, Takahashi S. A case of mild encephalitis/encephalopathy with a reversible splenial lesion during Mycoplasma pneumoniae infection. Nihon Shonika Gakkasi Zasshi. 2012;116: 1255. [in Japanese].
20. Uchida Y, Morita H, Miyazaki K, Adachi S, Tatebayashi K, Kaneko H. A case of menimgoencephalitis with a reversible splenial lesion due to Mycoplasma pneumoniae infection. Shoni Kansen Menneki. 2013;25:201-2. [in Japanese].

21. Waites KB. What's new in diagnostic testing and treatment approaches for Mycoplasma pneumoniae infections in children? Adv Exp Med Biol. 2011;719:47-57.

22. Chang HY, Chang LY, Shao PL, Lee PI, Chen JM, Lee CY, et al. Comparison of real-time polymerase chain reaction and serological tests for the confirmation of Mycoplasma pneumoniae infection in children with clinical diagnosis of atypical pneumonia. J Microbiol Immunol Infect. 2014;47:137-44.

23. Ozaki T, Nishimura N, Ahn J, Watanabe N, Muto T, Saito A, et al. Utility of a rapid diagnosis kit for Mycoplasma pneumoniae pneumonia in children, and the antimicrobial susceptibility of the isolates. J Infect Chemother. 2007; 13:204-7.

24. Shibuya H, Osamura K, Hara K, Hisada T. Clinically mild encephalitis/ encephalopathy with a reversible splenial lesion due to Mycoplasma pneumoniae infection. Intern Med. 2012;51:1647-8.

25. Zhou Y, Zhang Y, Sheng Y, Zhang L, Shen Z, Chen Z. More complications occur in macrolide-resistant than in macrolide-sensitive Mycoplasma pneumoniae pneumonia. Antimicrob Agents Chemother. 2014;58:1034-8.

26. Kashiwagi M, Tanabe T, Shimakawa S, Nakamura M, Murata S, Shabana K, et al. Clinico-radiological spectrum of reversible splenial lesions in children. Brain Dev. 2014;36:330-6.

27. Lin JJ, Hsia SH, Wu CT, Wang HS, Lin KL. Mycoplasma pneumoniae-related postencephalitic epilepsy in children. Epilepsia. 2011;52:1979-85.

28. Kolski H, Ford-Jones EL, Richardson S, Petric M, Nelson S, Jamieson F, et al. Etiology of acute childhood encephalitis at the hospital for sick children, Toronto, 1994-1995. Clin Infect Dis. 1998;26:398-409.

29. Lin WC, Lee PI, Lu CY, Hsieh YC, Lai HP, Lee CY, et al. Mycoplasma pneumoniae encephalitis in childhood. J Microbiol Immunol Infect. 2002;35:173-8.

30. Knyazeva MG. Splenium of corpus callosum: patterns of interhemispheric interaction in children and adults. Neural Plast. 2013;2013:639430. doi:10. 1155/2013/639430.

31. Gallucci M, Limbucci N, Paonessa A, Caranci F. Reversible focal splenial lesions. Neuroradiology. 2007;49:541-4.

32. Al-Zaidy SA, MacGregor D, Mahant S, Richardson SE, Bitnun A. Neurological complications of PCR-proven M. pneumoniae Infections in children: prodromal illness duration may reflect pathogenetic mechanism. Clin Infect Dis. 2015;61:1092-8

33. Hu CF, Wang CC, Chen SJ, Perng CL, Yang HY, Fan HC. Prognostic values of a combination of intervals between respiratory illness and onset of neurological symptoms and elevated serum IgM titers in Mycoplasma pneumoniae encephalopathy. J Microbiol Immunol Infect. 2014;47:497-502.

34. Gao J, Yue B, Li H, Chen R, Wu C, Xiao M. Epidemiology and clinical features of segmental/lobar pattern Mycoplasma pneumoniae pneumonia: a tenyear retrospective clinical study. Exp Ther Med. 2015;10:2337-44.

35. Daxboeck F, Blacky A, Seidl R, Krause R, Assadian O. Diagnosis, treatment, and prognosis of Mycoplasma pneumoniae childhood encephalitis: systematic review of 58 cases. J Child Neurol. 2004;19:865-71.

36. Takanashi J, Tada H, Maeda M, Suzuki M, Terada H, Barkovich AJ. Encephalopathy with a reversible splenial lesion is associated with hyponatremia. Brain Dev. 2009;31:217-20.

37. Ke C, Poon WS, Ng HK, Lai FM, Tang NL, Pang JC. Impact of experimental acute hyponatremia on severe traumatic brain injury in rats: influences on injuries, permeability of blood-brain barrier, ultrastructural features, and aquaporin-4 expression. Exp Neurol. 2002;178:194-206.

38. Pan JJ, Zhao YY, Lu C, Hu YH, Yang Y. Mild encephalitis/encephalopathy with a reversible splenial lesion: five cases and a literature review. Neurol Sci. 2015;36:2043-51.

39. Miyata R, Tanuma N, Hayashi M, Imamura T, Takanashi J, Nagata R, et al. Oxidative stress in patients with clinically mild encephalitis/encephalopathy with a reversible splenial lesion (MERS). Brain Dev. 2012;34:124-7.

40. Bettcher BM, Watson CL, Walsh CM, Lobach IV, Neuhaus J, Miller JW, et al. Interleukin-6, age, and corpus callosum integrity. PLoS One. 2014;9:e106521.

41. Brannan TS, Maker HS, Raes I, Weiss C. Regional distribution of glutathione reductase in the adult rat brain. Brain Res. 1980;200:474-7.

42. Gable MS, Gavali S, Radner A, Tilley DH, Lee B, Dyner L, et al. Anti-NMDA receptor encephalitis: report of ten cases and comparison with viral encephalitis. Eur J Clin Microbiol Infect Dis. 2009;28:1421-9.

43. Zhang J, Liu J, Fox HS, Xiong H. N-methyl-D-aspartate receptor-mediated axonal injury in adult rat corpus callosum. J Neurosci Res. 2013;91:240-8. 
44. Xiu Y, Kong XR, Zhang L, Qiu X, Gao Y, Huang CX, et al. The myelinated fiber loss in the corpus callosum of mouse model of schizophrenia induced by MK-801. J Psychiatr Res. 2015;63:132-40.

45. Tada H, Takanashi J, Barkovich AJ, Oba H, Maeda M, Tsukahara H, et al.

Clinically mild encephalitis/encephalopathy with a reversible splenial lesion. Neurology. 2004;63:1854-8.

Submit your next manuscript to BioMed Central and we will help you at every step:

- We accept pre-submission inquiries

- Our selector tool helps you to find the most relevant journal

- We provide round the clock customer support

- Convenient online submission

- Thorough peer review

- Inclusion in PubMed and all major indexing services

- Maximum visibility for your research

Submit your manuscript at www.biomedcentral.com/submit 